\title{
Impacts of General and Spinal Anaesthesia on Short-Term Cognitive Function and Mental Status in Elderly Patients Undergoing Orthopaedic Surgery
}

\author{
Xianping Zhang, Qingyong Dong and Jun Fang
}

\begin{abstract}
Objective: To investigate the impacts of general and spinal anesthesia on short-term cognitive function and mental status in elderly patients undergoing orthopaedic surgery.

Study Design: An experimental study.

Place and Duration of Study: Department of Anesthetics, the Central People's Hospital of Tengzhou City, Shandong Province, China, from December 2016 to December 2017.

Methodology: A total of 80 elderly patients undergoing orthopaedic surgery were selected and randomly divided into the observation group and the control group, 40 cases in each group. The observation group underwent spinal anesthesia, and the control group underwent general anaesthesia. Eye opening time, language presentation time etc.in the two groups were compared.

Results: The eye opening time and language presentation time in observation group were all lower than those in control group (both $p<0.001$ ). At 1,3 and 6 hours after surgery, the mini-mental state examination (MMSE) scores and the amplitudes of the P300 wave of observation group were all higher than those of the control group (all $p<0.001$ ), the latencies of the P300 wave in observation group were all lower than control group (all p<0.001). At $24 \mathrm{~h}$ after surgery, the number of cases suffering postoperative cognitive dysfunction (POCD) in the observation group was lower than that of the control group $(p=0.039)$.

Conclusion: Compared with general anaesthesia, spinal anesthesia can effectively shorten the eye opening time and language presentation time in elderly patients undergoing orthopaedic surgery. It also has few impacts on the short-term cognitive function and mental status of such patients, with lower incidence of POCD.
\end{abstract}

Key Words: Orthopaedics, Surgery, Elderly patients, Spinal anesthesia, General anaesthesia, Postoperative cognitive dysfunction.

\section{INTRODUCTION}

In the recent years, the incidence of bone injury in elderly patients ( $\geq 60$ years of age) has been increasing, and the vast majority of cases are treated by surgery. However, elderly patients ( $\geq 60$ years of age) often experience central nervous system complications after surgery, manifested as mental confusion, fear and anxiety, memory loss, social dysfunction, and other symptoms which are also known as postoperative cognitive dysfunction (POCD).1,2 POCD will reduce patients' self-care ability and quality of life, and increase the incidence of postoperative complications and mortality. 3,4 At present, the pathogenesis of POCD in the elderly is still not clear. Some scholars believe that anaesthetic agents and methods may affect the central nervous function of elderly patients, and contribute to the occurrence and development of POCD.5,6 In addition,

Department of Anesthetics, the Central People's Hospital of

Tengzhou City, Shandong Province, China

Correspondence: Jun Fang, Department of Anesthetics, the Central People's Hospital of Tengzhou City,

Shandong Province, 277599 China

E-mail: xfcwxpedgeu09@163.com

Received: April 09, 2018; Accepted: September 13, 2018 due to the decline of physiological functions in elderly patients, those undergoing orthopaedic surgery may suffer a higher risk during anaesthesia. Effective anaesthetic methods should be selected to reduce the negative impacts such as POCD brought by the surgery. 7,8 Spinal anaesthesia refers to the injection of local anaesthetics into the subarachnoid or epidural space of the spinal canal to block the corresponding spinal nerve roots and produce anaesthetic effects in the dominating area. 9,10 At present, spinal anaesthesia is an anaesthetic method commonly used in scheduled orthopaedic surgery. With the maturity and wide application of spinal anaesthesia technique, its advantages have gradually received attention. ${ }^{11}$

The aim of this study was to investigate the impacts of general and spinal anaesthesia on short-term cognitive function and mental status in elderly patients undergoing orthopaedic surgery, in order to provide reference for anaesthesia in elderly patients undergoing orthopaedic surgery.

\section{METHODOLOGY}

This study was done in the Department of Anesthetics, the Central People's Hospital of Tengzhou City, Shandong Province, China, from December 2016 to 
December 2017. A total of 80 elderly patients undergoing orthopaedic surgery were selected as the research subjects. Inclusion criteria were patients with normal consciousness before surgery, age $\geq 60$ years, and $\geq 9$ years of education in China. Exclusion criteria were patients with neurological diseases, cognitive disorders, history of long-term administration of sedatives and those with malignant tumours. The subject was approved by the medical ethics committee of hospital, and all patients have signed an informed consent. The 80 patients were divided into an observation group and a control group in accordance with the random number table, 40 cases in each group. After the two groups of patients entered the operating room, the peripheral venous channel was routinely opened; blood pressure, electrocardiogram, pulse oxygen saturation, and so on, were monitered via monitor.

The control group received general anaesthesia through intravenous drip midazolam $0.05 \mathrm{mg} / \mathrm{kg}$, propofol 1.5 $\mathrm{mg} / \mathrm{kg}$, fentanyl $0.4 \mu \mathrm{g} / \mathrm{kg}$, and vecuronium bromide 0.1 $\mathrm{mg} / \mathrm{kg}$. Anaesthesia ventilation respiratory parameters were tidal volume of $6-8 \mathrm{ml} / \mathrm{kg}$, respiratory quotient $1: 2$, and oxygen flow at $1 \mathrm{~L} / \mathrm{min}$. The anesthetic dosage was adjusted through clinical observation of the change of cerebral state index (CSI) during general anesthesia and according to the value of CIS. The observation group received spinal anaesthesia. Epidural puncture was performed on the intervertebral space of the $L_{3-4}$ and implementation management of epidural anaesthesia, then $1 \mathrm{ml}$ of $0.5 \%$ bupivacaine was injected, if necessary supplemented by $0.25 \%$ lidocaine for anaesthesia.

Eye opening time and language presentation time in the two groups were recorded and compared. At 1, 3, 6 and 24 hours after surgery, cognitive function assessment was performed on the two groups of patients by using the MMSE. The total score of MMSE is 30 . Higher the score, the better the patient's cognitive function will be. The incidence of postoperative cognitive dysfunction (POCD) was compared between the two groups at $24 \mathrm{~h}$ after surgery. The Nicolet Viking Quest EMG/EP system was used to detect the latency and amplitude of the P300 wave in event-related potentials (ERPs) in both the groups. Auditory novel oddball tasks were used. Auditory target/non-target stimulus sequences were selected to induce the event-related potentials of the subjects. The whole experiment was conducted in a shielded soundproof room. The subjects sat on soft chairs, relaxed the whole body muscles, closed their eyes and kept their heads clear and focused; the observational indicators were set as the latency and amplitude of the target stimulus P300.

SPSS 21.0 statistical software was used for data analysis. Measurement data were expressed as mean \pm standard deviation. The independent samples t-test was used for comparison between the two groups. Count data were expressed as frequencies with percentages and the $\mathrm{x} 2$ test was used to compare the count data between the two groups. A difference with a $p$-value less than 0.05 was considered statistically significant.

\section{RESULTS}

Of the 80 patients, there were $42(52.50 \%)$ males and 38 $(47.50 \%)$ females; aged $61-74$ years, mean $69.36 \pm 2.57$ years; body weight $57-73 \mathrm{Kg}$, mean $65.71 \pm 3.58 \mathrm{Kg}$; mean $12.51 \pm 1.76$ years of education in China. The procedures were total hip replacement $(37,46.25 \%)$, hemi hip replacement $(22,27.50 \%)$, and femoral fracture fixation $(21,26.25 \%)$.

The eye opening time of the observation group was $2.42 \pm 0.95$ minutes, lower than that of the control group $3.35 \pm 0.66$ minutes $(p<0.001)$. The language presentation time of the observation group was $3.73 \pm 0.86$ minutes, lower than that of the control group $9.15 \pm 1.06$ minutes

Table I: MMSE scores in the two groups (score).

\begin{tabular}{|c|c|c|c|c|c|c|c|c|c|}
\hline \multirow[t]{2}{*}{ Groups } & \multirow[t]{2}{*}{$\mathrm{n}$} & \multicolumn{2}{|c|}{ At $1 \mathrm{~h}$ after surgery } & \multicolumn{2}{|c|}{ At $3 \mathrm{~h}$ after surgery } & \multicolumn{2}{|c|}{ At $6 \mathrm{~h}$ after surgery } & \multicolumn{2}{|c|}{ At $24 \mathrm{~h}$ after surgery } \\
\hline & & Mean $\pm S D$ & p-value & Mean $\pm S D$ & p-value & Mean \pm SD & p-value & Mean \pm SD & $p$-value \\
\hline Control group & 40 & $20.78 \pm 1.09$ & $<0.001$ & $22.43 \pm 1.80$ & $<0.001$ & $23.71 \pm 1.54$ & $<0.001$ & $27.14 \pm 2.03$ & 0.145 \\
\hline Observation group & 40 & $24.37 \pm 2.32$ & & $25.86 \pm 2.40$ & & $26.98 \pm 1.37$ & & $27.85 \pm 2.28$ & \\
\hline
\end{tabular}

Table II: Latencies of the P3 wave in the the two groups.

\begin{tabular}{|c|c|c|c|c|c|c|c|c|c|}
\hline \multirow[t]{2}{*}{ Groups } & \multirow[t]{2}{*}{$\mathrm{n}$} & \multicolumn{2}{|c|}{ At $1 \mathrm{~h}$ after surgery } & \multicolumn{2}{|c|}{ At $3 \mathrm{~h}$ after surgery } & \multicolumn{2}{|c|}{ At $6 \mathrm{~h}$ after surgery } & \multicolumn{2}{|c|}{ At $24 \mathrm{~h}$ after surgery } \\
\hline & & Mean $\pm S D$ & $p$-value & Mean \pm SD & $p$-value & Mean $\pm S D$ & $p$-value & Mean $\pm S D$ & $p$-value \\
\hline Control group & 40 & $441.53 \pm 20.25$ & $<0.001$ & $416.74 \pm 8.10$ & $<0.001$ & $393.66 \pm 21.77$ & $<0.001$ & $310.95 \pm 4.05$ & 0.190 \\
\hline Observation group & 40 & $362.76 \pm 15.19$ & & $331.15 \pm 10.13$ & & $312.97 \pm 11.14$ & & $309.51 \pm 5.57$ & \\
\hline
\end{tabular}

Table III: Amplitudes of the P3 wave in the the two groups.

\begin{tabular}{|c|c|c|c|c|c|c|c|c|c|}
\hline \multirow[t]{2}{*}{ Groups } & \multirow[t]{2}{*}{$\mathrm{n}$} & \multicolumn{2}{|c|}{ At $1 \mathrm{~h}$ after surgery } & \multicolumn{2}{|c|}{ At $3 \mathrm{~h}$ after surgery } & \multicolumn{2}{|c|}{ At $6 \mathrm{~h}$ after surgery } & \multicolumn{2}{|c|}{ At $24 \mathrm{~h}$ after surgery } \\
\hline & & Mean \pm SD & p-value & Mean \pm SD & $\mathrm{p}$-value & Mean \pm SD & $p$-value & Mean \pm SD & $\mathrm{p}$-value \\
\hline Control group & 40 & $6.25 \pm 0.41$ & $<0.001$ & $8.36 \pm 0.72$ & $<0.001$ & $9.92 \pm 0.28$ & $<0.001$ & $12.78 \pm 0.40$ & 0.966 \\
\hline Observation group & 40 & $9.73 \pm 0.27$ & & $10.87 \pm 0.61$ & & $12.11 \pm 1.06$ & & $13.03 \pm 0.63$ & \\
\hline
\end{tabular}


$(p<0.001)$. The MMSE scores of the observation group at 1,3 and 6 hours after surgery were all higher than those of the control group (all <0.001). There was no significant difference in the MMSE scores between the two groups at $24 \mathrm{~h}$ after surgery $(p=0.145$, Table I).

At $1 \mathrm{~h}, 3 \mathrm{~h}$ and $6 \mathrm{~h}$ after surgery, the latencies of the $\mathrm{P} 300$ wave in the observation group were all lower than the control group (all $p<0.001$ ), and the amplitudes of the P300 wave in the observation group were all higher than the control group (all $p<0.001$ ). At $24 \mathrm{~h}$ after surgery, there were no significant differences between the two groups in both the latency and the amplitude of the P300 wave ( $p=0.190$, and 0.966, Tables II and III).

At $24 \mathrm{~h}$ after surgery, the number of cases suffering POCD in the observation group was $6(15.00 \%)$, lower than $14(35.00 \%)$ cases of the control group $(p=0.039)$.

\section{DISCUSSION}

Cognitive dysfunction can occur in patients of different ages, and the pathogenic factors are complex. Some scholars believe that age is positively related to the occurrence of the cognitive dysfunction, which may be related to the occurrence of pathophysiological changes in the elderly. ${ }^{12}$ The brain tissues of elderly patients show degenerative changes, and the number of nerve cells is significantly reduced compared with young people. The ability of neurons to supply energy is reduced, and the metabolism of brain tissues also gradually goes down. At the same time, elderly patients have decline in liver and kidney functions and decreased levels of tolerance and elimination to drugs, all which may lead to postoperative cognitive dysfunction in them. ${ }^{13}$ Some studies have also found that anaesthetic drugs can cause abnormal regulation of neurotransmitters and receptors in the human central nervous system, leading to decreased levels of learning and memory in patients after surgery. 14 Cognitive dysfunction caused by anaesthetic drugs perform more prominently in elderly patients. Body functions decline with age, and the incidence of postoperative cognitive dysfunction in the elderly is significantly increased. ${ }^{15}$

General anaesthesia is the most common method of anaesthesia used in early fracture surgery. However, large dosages of anaesthetic drugs can significantly affect the signal transmission among neurons, change the protein expression of nerve cells, lead to nerve cell apoptosis, and reduce cerebral blood flow. So the method has certain drawbacks. ${ }^{16,17}$ Spinal anesthesia is a method of injecting drugs into the cavity of the spinal canal to block nerve conduction and then achieve an anaesthetic effect. The target of this method changes from the whole body of the patient to local surgical sites. At this time, the anaesthetic drug will no longer have a serious impact on the blood circulation of the brain; and the nerve cell apoptosis of the patient can also be suppressed. 18 In theory, spinal anesthesia can decrease the dosages of anaesthetic drugs compared to general anaesthesia, promote postoperative recovery, and reduce neurological damage. 19 In this study, the impacts of general anaesthesia and spinal anesthesia on elderly orthopaedic patients were compared. From the results of the study, the observation group using spinal anesthesia showed lower data than the control group in eye opening time and language presentation time. This illustrates that spinal anesthesia can effectively shorten the eye opening time and language presentation time in elderly patients undergoing orthopaedic surgery.

MMSE, as a commonly used assessment tool for mental status and cognitive function, can well reflect a patient's mental status and cognitive function. 20 From the MMSE scores of the two groups in this study, the MMSE scores of the observation group at $1 \mathrm{~h}, 3 \mathrm{~h}$ and $6 \mathrm{~h}$ after surgery were all higher than those of the control group. This suggested that spinal anesthesia had fewer impacts on the mental status and cognitive function of elderly patients compared with general anaesthesia. However, there was no significant difference in the MMSE scores at $24 \mathrm{~h}$ after surgery between the two groups, which may be related to the disappeared metabolism of anaesthetics.

The endogenous component P300 of auditory eventrelated potentials is not completely affected by the physical properties of sound stimuli and is closely related to the cognitive information process. ${ }^{21} \mathrm{P} 300$ and its subcomponents reflect physiological and psychological functions related to cognitive processes such as perception and memory. The P300 amplitude depends on how difficult it is to distinguish between target and standard stimuli; the P300 latency reflects the time it takes from the appearance of a stimulus to the awareness of the brain to the stimulus signal and then to wakefulness. A decreased amplitude of the P300 wave reflects a decreased involuntary attention of a patient. An increased latency of the P300 wave indicates a decreased speed of a patient in response to selective attention. This study showed that the P300 latencies in the observation group at $1 \mathrm{~h}, 3 \mathrm{~h}$ and $6 \mathrm{~h}$ after surgery were all significantly lower than the control group. The P300 amplitudes in the observation group at $1 \mathrm{~h}, 3 \mathrm{~h}$ and $6 \mathrm{~h}$ after surgery were significantly higher than the control group, that is, spinal anesthesia had fewer impacts on the cognitive function expressed by P300. This conclusion is consistent with previously published results. ${ }^{22}$ At $24 \mathrm{~h}$ after surgery, there were no significant differences between the two groups in the latency and amplitude of the P300 wave, which may be related to the disappeared metabolism of anaesthetics in patients. At $24 \mathrm{~h}$ after surgery, the incidence of POCD in the observation group was lower than the control group. It suggested that the elderly orthopaedic patients suffered from varying degrees of cognitive impairment after both general anaesthesia and spinal anesthesia. However, 
general anaesthesia showed greater impacts on the short-term cognitive dysfunction after surgery than spinal anesthesia, with a higher incidence of POCD. The limitations of this study is measurement of cognitive function by using MMSE and P300 latency. There may be some one-sidedness.

\section{CONCLUSION}

Compared with general anaesthesia, spinal anaesthesia can effectively shorten the eye opening time and language presentation time in elderly patients undergoing orthopaedic surgery. It also has lesser impact on the short-term cognitive function and mental status of such patients, with lower incidence of POCD.

\section{REFERENCES}

1. Steinmetz J, Christensen KB, Lund T, Lohse N, Rasmussen LS. Long-term consequences of postoperative cognitive dysfunction. Anesthesiology 2009; 110:548-55.

2. Newman S, Stygall J, Hirani S, Shaefi S, Maze M. Postoperative cognitive dysfunction after noncardiac surgery: A systematic review. Anesthesiology 2007; 106:572-90.

3. Rohan D, Buggy DJ, Crowley S, Ling FKH, Gallagher H, Reganm C, et al. Increased incidence of postoperative cognitive dysfunction $24 \mathrm{hr}$ after minor surgery in the elderly. Can J Anaesth 2005; 52:137-42.

4. Wang Y, Huang A, Gan L, Bao Y, Zhu W, Hu Y, et al. Screening of potential genes and transcription factors of postoperative cognitive dysfunction via bioinformatics methods. Med Sci Monit 2018; 24:503-10.

5. Mandal PK, Saharan S, Penna O, Fodale V. Anesthesia issues in central nervous system disorders. Curr Aging Sci 2016; 9:116-43.

6. Aurini L, White PF. Anesthesia for the elderly outpatient. Curr Opin Anaesthesiol 2014; 27:563-75.

7. Liebert AD, Chow RT, Bicknell BT, Varigos E. Neuroprotective effects against pocd by photobiomodulation: evidence from assembly/disassembly of the cytoskeleton. $J$ Exp Neurosci 2016; 1:1-19.

8. Oktay F, Cömert D, Gökkaya NK, Ozbudak SD, Uysal H. Bone age in children with obstetrical brachial plexus palsy: Effect of peripheral nerve injury on skeletal maturation. J Child Neurol 2014; 29:203-9.

9. Rocchi R, Lombardi C, Marradi I, Paolo MD, Cerase A. Intracranial and intraspinal hemorrhage following spinal anesthesia. Neurol Sci 2009; 30:393-6.

10. Elwood D, Koo C. Intraspinal hematoma following neuraxial anesthesia and low-molecular-weight heparin in two patients: risks and benefits of anticoagulation. PMR 2009; 1:389-96.
11. Lee KK, Lee MY, Han DY, Jung HJ, Joo MC. Effects of bladder function by early tamsulosin treatment in a spinal cord injury rat model. Ann Rehabil Med 2014; 38:433-42.

12. De RD, Berardi D, Menchetti M, Ferrari G, Serretti A, Dalmonte E, et al. Occurrence of cognitive impairment and dementia after the age of 60: a population-based study from northern italy. Dement Geriatr Cogn Disord 2005; 19:97-105.

13. Foki T, Hitzl D, Pirker W, Novak K, Pusswald G, Auff E, et al. Assessment of individual cognitive changes after deep brain stimulation surgery in parkinson's disease using the neuropsychological test battery vienna short version. Wien Klin Wochenschr 2017; 129:564-71.

14. Westphalen RI, Desai KM, Hemmings HC. Presynaptic inhibition of the release of multiple major central nervous system neurotransmitter types by the inhaled anaesthetic isoflurane. Br J Anaesth 2013; 110:592-9.

15. Rasmussen LS, Johnson T, Kuipers HM, Kristensen D, Siersma VD, Vila $P$, et al. Does anaesthesia cause postoperative cognitive dysfunction? A randomised study of regional versus general anaesthesia in 438 elderly patients. Acta Anaesthesiol Scand 2003; 47:260-6.

16. Aksoy M, Ince I, Ahiskalioglu A, Tör I, Dostbil A, Alici HA, et al. Our experiences of anesthesia in lower and upper extremity surgeries: a retrospective analysis of last six years. Anestezi Dergisi 2014; 22:99-104.

17. Kim YS, Chae YK, Choi YS, Min JH, Ahn SW, Yoon JW, et al. A comparative study of emergence agitation between sevoflurane and propofol anesthesia in adults after closed reduction of nasal bone fracture. Korean $J$ Anesthesiol 2012; 63:48-53.

18. Eac P, Oxenham M, Lam KS. Intraspinal anomalies in earlyonset idiopathic scoliosis. Bone Joint J 2017; 99-B:829-33.

19. Saadoun S, Chen S, Papadopoulos MC. Intraspinal pressure and spinal cord perfusion pressure predict neurological outcome after traumatic spinal cord injury. $J$ Neurol Neurosurg Psychiatry 2017; 88:452-3.

20. Ciesielska N, Sokolowski R, Mazur E, Podhorecka M, PolakSzabela A, Kedziora-Kornatowska K. Is the Montreal cognitive assessment (MoCA) test better suited than the mini-mental state examination (MMSE) in mild cognitive impairment (MCl) detection among people aged over 60? Meta-analysis. Psychiatr Pol 2016; 50:1039-52.

21. Dujardin K, Derambure P, Bourriez JL, Jacquesson JM, Guieu JD. P300 component of the event-related potentials (ERP) during an attention task: effects of age, stimulus modality and event probability. Int J Psychophysiol 1993; 14:255-67.

22. Weng LJ. Comparison of the efficacy of two kinds of anesthesia in elderly patients with bone fracture. $J$ Hunan Norm Univ (Med Sci) $2017 ;$ 14:129-31. 